\title{
Two methods for measuring internal velocity of debris flows in the laboratory
}

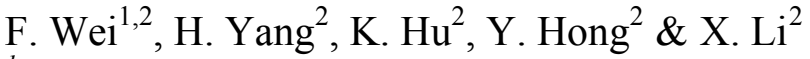 \\ ${ }^{1}$ Key Laboratory of Mountain Hazards and Earth Surface Processes, \\ Chinese Academy of Sciences, China \\ ${ }^{2}$ Institute of Mountain Hazards and Environment, \\ Chinese Academy of Sciences, China
}

\begin{abstract}
The velocity of debris flows is a very important parameter for debris flow research and design of debris flow control works. The velocity of debris flows can be divided into surface velocity and internal velocity. The surface velocity of debris flows has been researched widely while the internal velocity is minimally researched because there is no available method for measuring internal velocity. In this paper, we developed two methods for measuring the internal velocity of debris flows in laboratory. One method is using impact pressure detecting, and the other is using shear forces detecting. In the former method, the internal velocity is calculated by the impact pressure detected by pressure sensors according to the relationship between velocity and kinetic pressure. In the later method, the internal velocity is calculated using the distance between two detecting sections and the time difference between the two waveforms of shear forces measured at both sections.
\end{abstract}

Keywords: debris flow, internal velocity, impact force, shear force, flume experiment.

\section{Introduction}

In the research of dynamics of debris flow and design of debris flow control works, the velocity of debris flows is a key parameter. The velocity of debris flows can be classified into surface velocity (at free surface of debris flow) and internal velocity (inside the debris flow). The surface velocity has been researched widely because it is easy to measure in the field and laboratory. Arattano and Marchi used ultrasonic sensors to detect the times of debris flow 
passing two observing sections then estimated the velocity of debris flow by calculating the arrival time difference and the distance between the two sections $[1,2]$. Berti et al. [3] and Itakura et al. [4] used ground vibration sensors (geophones) to detect the times of debris flow passing two observing sections and calculated the velocity of debris flow. Suwa et al. [5], Zhang [6], Itakura et al. [7] and Stepanov [8] employed Doppler radar to measure the surface velocity of debris flow with the Doppler effect. Prochaska et al. used video analysis software to investigate the velocities of different sized particles within debris flows [9]. But the internal velocity of debris flows is researched limitedly because it is more difficult to be measured. Conventional current velometers would be destroyed by large impact force of this heterogen ous fluid containing gravels and boulders. So there is no effective method for measuring the internal velocity of debris flows now. Hanisch et al. [10] and Itakura et al. [11] tried to use instruments immersed in the debris flow but these instruments were destroyed in the process. In this paper, we developed two methods for measuring the internal velocity of debris flows in laboratory.

\section{Internal velocity of debris flows in laboratory}

The debris flow in laboratory is usually made in a flume. The velocity of debris flows can be divided into surface velocity and internal velocity according to its position. The velocity of the fluid surface is surface velocity and the velocity in the fluid inner is internal velocity (Figure 1). The velocity in both flume inwalls and the bottom is also called internal velocity here because it is under the fluid surface and can't be detected as measuring surface velocity. Because the velocities in fluid inner, inwall or bottom are different and their detecting conditions are different too, two different methods of measuring internal velocity of debris flow are developed for measuring the velocity in fluid inner and velocity on inwall and bottom of flume.

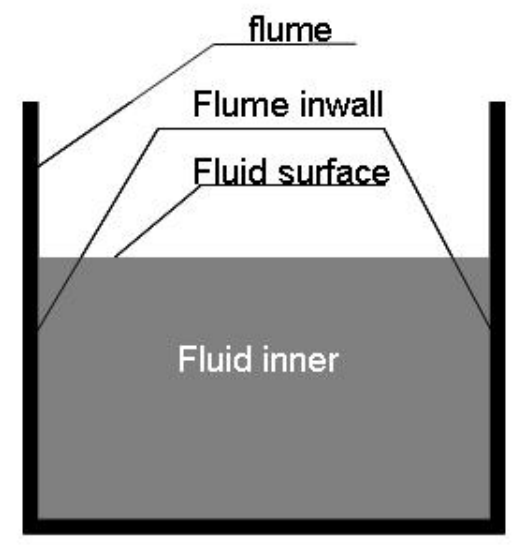

Figure 1: Scheme of the debris flow flume in laboratory. 


\section{Method by impact pressure detecting for measuring velocity in fluid inner}

\subsection{System of debris flow impact pressure detecting}

The system for detecting impact pressure of debris flow consists of pressure sensors, an upright post, a data acquisition instrument and a computer for data storage as shown in Figure 2.

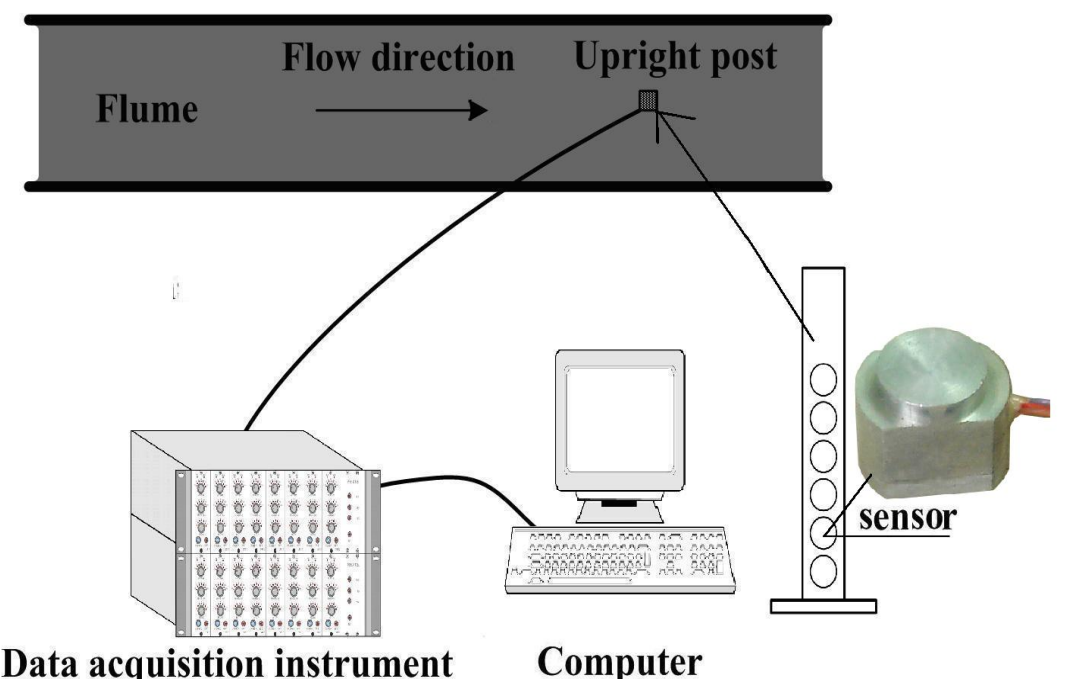

Figure 2: $\quad$ Scheme of the system for detecting impact pressure of debris flow.

A group of impact pressure sensors is needed in this system to detect impact pressures at different depths. The sensor used in this system is a strain transducer with a circular front. An upright post is needed in this system to fix the sensors. It has several circular openings to install them. A data acquisition instrument with multiple independent channels of signal input is needed in this system. All channels can acquire data in synchronism.

In the experiment of detecting the impact pressure with this system, a digital video camera is installed above the flume to monitor and record the movement of floaters for measuring the surface velocity of debris flow and a laser diastimeter is installed to record debris flow depth while this system is installed to detect the impact pressure of debris flow.

\subsection{Velocity calculation}

For homogeneous fluid, the relationship between the kinetic pressure and the velocity can be described by following equation. 


$$
p_{\mathrm{k}}=\frac{1}{2} \rho_{\mathrm{f}} v^{2}
$$

in which $P_{\mathrm{k}}$ is kinetic pressure, $\rho_{\mathrm{f}}$ is fluid density and $v$ is velocity.

However, debris flow is a heterogeneous fluid. This relationship for debris flow is often corrected by a coefficient as following.

$$
p_{\mathrm{d}}=k \rho_{\mathrm{c}} v^{2}
$$

where $P_{\mathrm{d}}$ is the kinetic pressure of debris flow, $\rho_{\mathrm{c}}$ is the debris flow density and $k$ is a coefficient.

So we can calculate the velocity of debris flow with following equation:

$$
\mathrm{v}=k \sqrt{P_{k} / \rho_{c}}
$$

where coefficient $k$ can be regressed from surface velocity and surface kinetic pressure data.

Of course, the kinetic pressure can't be detected directly by this impact pressure detecting system. The pressure detected by the system is the sum of kinetic pressure and static pressure. But we can calculate the static pressure with depth of debris flow detected by the laser diastimeter. Then the kinetic pressure is the impact pressure minus static pressure.

\section{Method by shear forces detecting for measuring velocity on inwall or bottom}

\subsection{System of debris flow shear force detecting}

The system for detecting shear force of debris flow consists of shear force sensors, brackets, a data acquisition instrument and a computer for data storage as shown in Figure 3. A shear force sensor group consisting of two sensors is needed for this system. If synchronous velocity measurements at different depths are required, multiple sensor groups should be available. The sensor is a type of strain transducer with a rectangular shear front. A data acquisition instrument with multiple independent channels of signal input is needed in this system. All channels can acquire data in synchronism.

\subsection{Velocity calculation}

In the system of detecting the shear force of debris flows, two sections ( $\Phi$ and $\Phi$ ') perpendicular to the direction of debris flow movement are set along the debris flow channel, and two points ( $\phi$ and $\phi$ ') respectively located on section $\Phi$ and $\Phi^{\prime}$ are selected to install shear force sensors (Figure 4). Both points are on the same inwall or bottom and their geometric positions in their sections should be the same. 


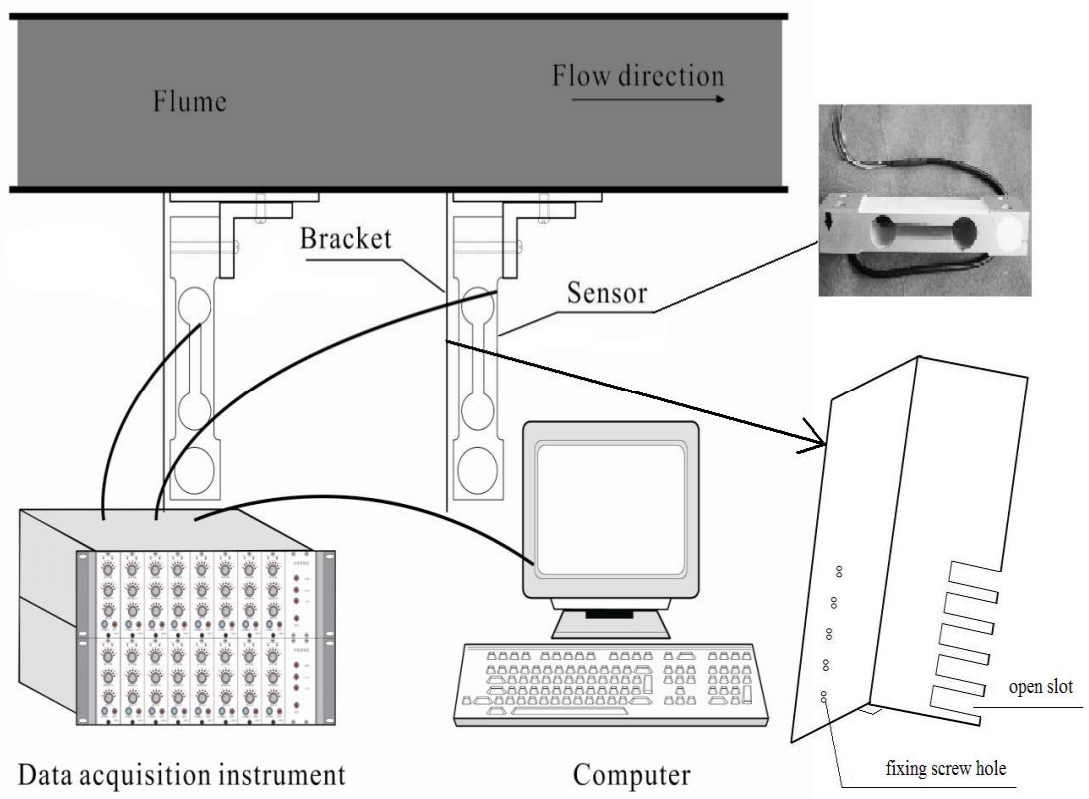

Figure 3: $\quad$ Scheme of system of detecting shear force.

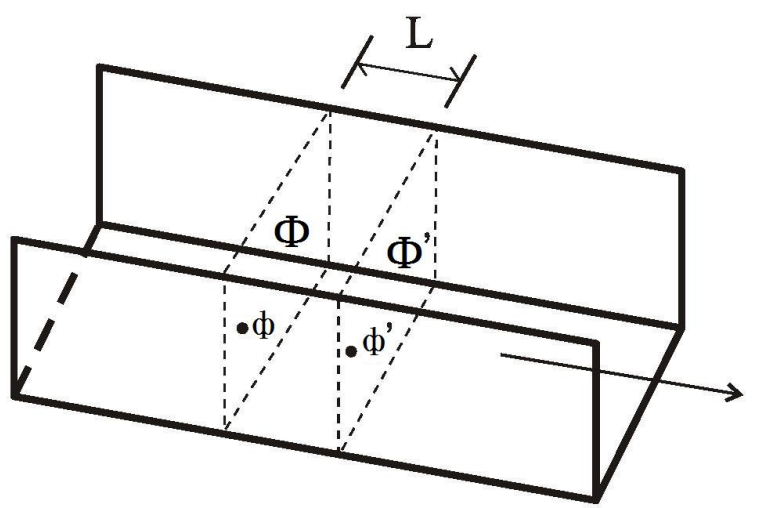

Debris flow direciton

Figure 4: $\quad$ Scheme of sections of debris flow channel.

The shear force in a debris flow at a given position is positively correlated with the internal velocity and fluid characteristics. If the distance $L$ between point $\phi$ and point $\phi^{\prime}$ 'is short, it can be assumed that the velocities and fluid characteristics of the debris flow passing through both points are very similar. Furthermore, it can be assumed that those characteristics of a fluid passing through both points are very similar also. So the shear force graphs on point $\phi$ 
and point $\phi^{\prime}$ are very similar in terms of waveforms except a time difference $\triangle t$ (Figure 5).

According to the data detected by the shear force sensors, the shear force graphs on two positions can be drawn and the time difference $\triangle t$ can be determined. The velocity of debris flow from point $\phi$ to point $\phi^{\prime}$ on the inwall or bottom of the flume can be computed with following equation

$$
v=L / \triangle t
$$

In fact, the velocity calculated with this method is the mean velocity between two detecting points. But we can estimate the velocity of debris flow on a position if the distance between two detecting points is short enough. Therefore the detecting sections should be the closest possible.

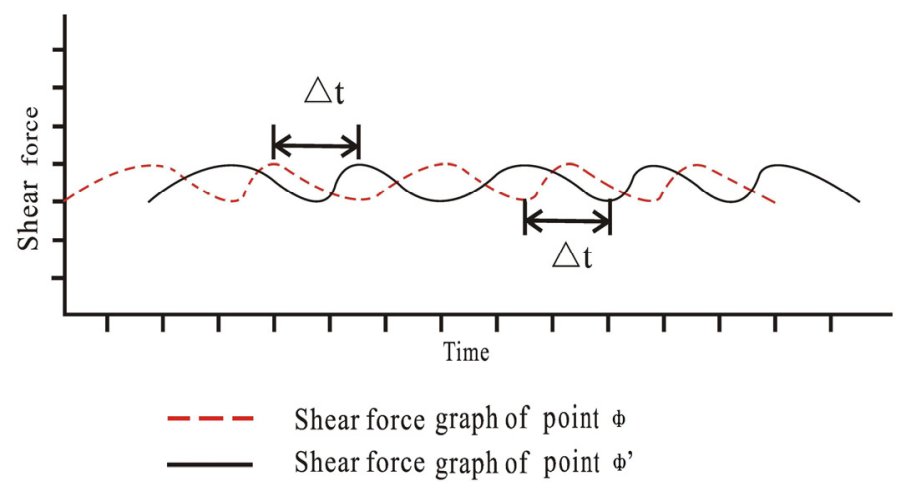

Figure 5: Scheme of shear force graph.

\section{Application of two methods of measuring internal velocity of debris flows}

A debris flow flume with $600 \mathrm{~cm}$ length and $30 \mathrm{~cm}$ width was made for debris flow movement experiment in Dongchuan Debris Flow Observation and Research Station, Chinese Academy of Sciences and both systems of measuring internal velocity of debris flows by detecting impact pressure and shear force were installed for measuring the internal velocity in the debris flow flume experiment (Figure 6 and Figure 7). The velocities in the fluid inner with different depths were measured with the method by impact pressure detecting and the velocities on the inwall with different depths were measured with the method by shear force detecting. 


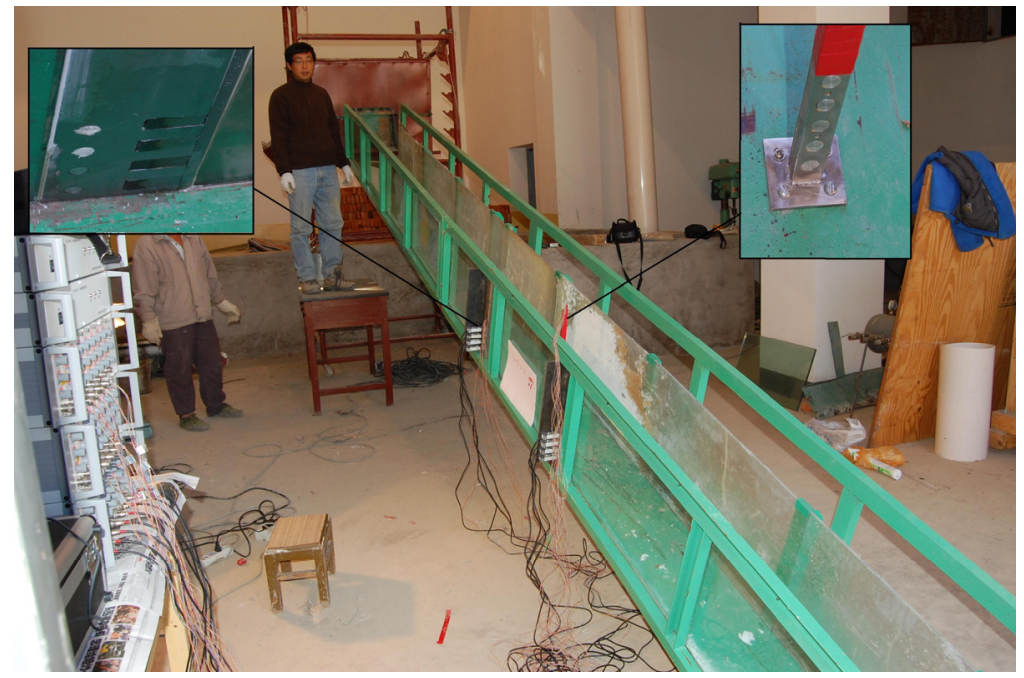

Figure 6: Flume and systems of measuring internal velocity of debris flows.

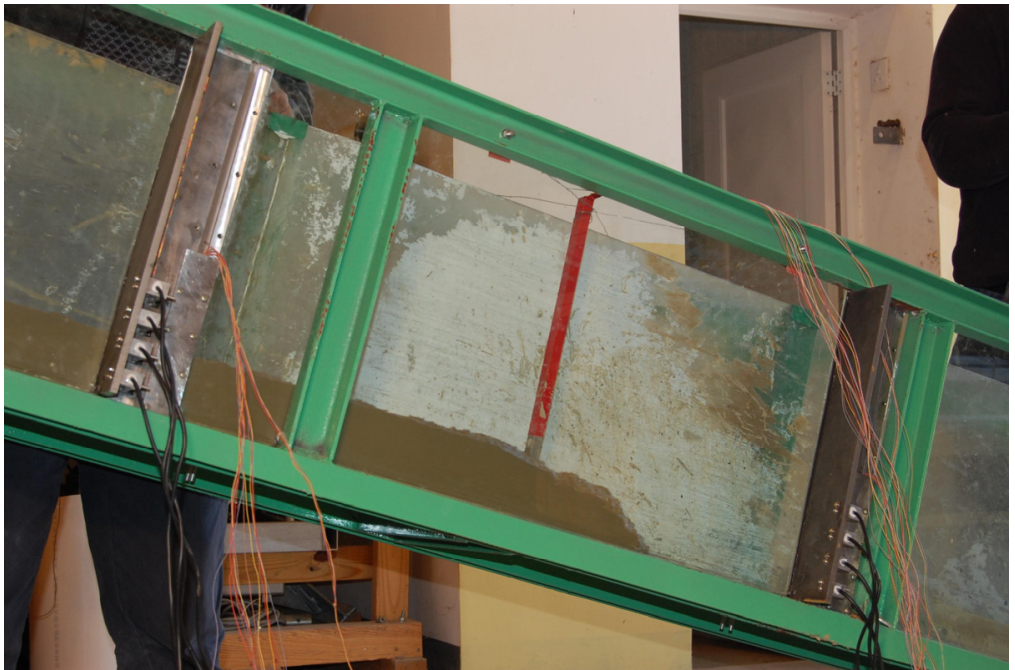

Figure 7: Experiment of measuring internal velocity of debris flows.

\subsection{Application of the method by impact pressure detecting}

In the experiment, the impact pressure sensors are a type of strain transducer. Their main technical parameters are illustrated in Table 1 . The data detected by all impact pressure sensors were acquired synchronously by the data acquisition instrument. At the same time, a video was taken during the experiment to detect the surface velocity of debris flow and the height of debris flow surface was 
Table 1: $\quad$ Main technical features of the impact pressure sensor.

\begin{tabular}{cc||cc}
\hline Parameter & Value & Parameter & Value \\
\hline $\begin{array}{c}\text { Measuring } \\
\text { range } \\
\text { Sensitivity }\end{array}$ & $60 \mathrm{~N}$ & Response frequency & $4 \mathrm{KHz}$ \\
Error & $\pm 0.05 \% \mathrm{~F} . \mathrm{S}$ & Overload capacity & $150 \% \mathrm{~F} . \mathrm{S}$ \\
\hline
\end{tabular}

detected by a laser diastimeter to determine the depth of each impact pressure sensor (Figure 8). The correction coefficient for calculating velocity based on kinetic pressure was determined according to the surface velocities analyzed from video images and impact pressure detected by the sensor which close to debris flow surface. In this experiment, the correction coefficient $k$ varied from 1.315 to 1.48 with a mean value 1.410 . After the correction coefficient and depths of debris flow are determined, the velocity of debris flow can be calculated by Equation 3 with the impact pressure detected by the system.
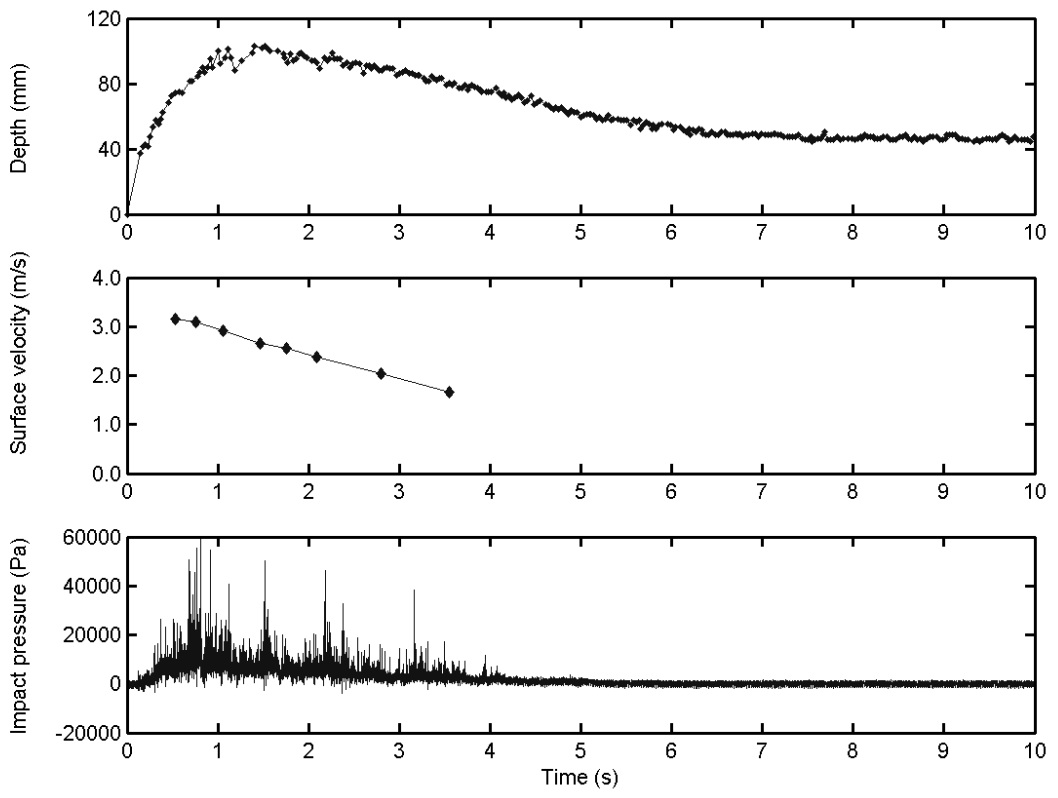

Figure 8: Graphs of debris flow depth, surface velocity and impact pressure.

\subsection{Application of the method by shear force detecting}

In the experiment, the shear force sensors are a type of strain transducer. Their main technical parameters are illustrated in Table 2. The data detected by all 
shear force sensors were acquired in synchronism by the data acquisition instrument. The Figure 9 illustrates two graphs of shear force detected by a pair of shear force sensors in a debris flow movement experiment. Two graphs have similar shape, but have an obvious time difference. It is easy to determine the time difference $\triangle t$. With this key parameter, the velocity can be calculated by Equation 4.

Table 2: $\quad$ Main technical parameters of shear force sensor.

\begin{tabular}{cc||cc}
\hline Parameter & Value & Parameter & Value \\
\hline Measuring range & $50 \mathrm{~N}$ & Response frequency & $2 \mathrm{KHz}$ \\
Sensitivity & $2 \pm 0.5 \mathrm{mV} / \mathrm{V}$ & Voltage & $9 \sim 15 \mathrm{~V} \mathrm{DC}$ \\
Error & $\pm 0.05 \% \mathrm{~F} . \mathrm{S}$ & Overload capacity & $150 \% \mathrm{~F} . \mathrm{S}$ \\
\hline
\end{tabular}

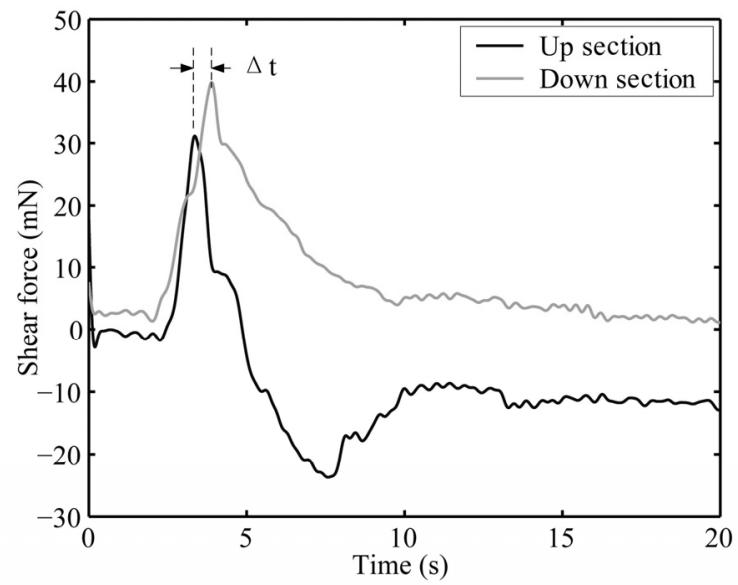

Figure 9: $\quad$ Graphs of shear force detected by a pair of shear force sensors.

\section{Conclusion}

(1) The velocity of debris flows can be divided into surface velocity and internal velocity according to its position. The velocity of the fluid surface is surface velocity and the velocity under the fluid surface is internal velocity. The internal velocity includes the velocity in the inner of fluid, on the inwall and bottom.

(2) There is a close relationship between the impact pressure and velocity of debris flows. A system of detecting the impact pressure of debris flow by pressure sensors was designed to measure the velocity in inner of debris flow. With this method of measuring internal velocity of debris flows, the 
surface velocity of debris flow should be measured at the same time to determine the correction coefficient for calculating velocity based on kinetic pressure, and the height of debris flow surface should be detected to determine the depth of each impact pressure sensor.

(3) The shear force in a debris flow at a given position is positively correlated with the internal velocity and fluid characteristics. A system of detecting the shear force on two same positions of two sections of the flume was designed to measure the velocity of debris flows on the inwall and bottom. The velocity is calculated according the distance between two sections and the time difference between two graphs of shear forces on two sections detected by the system.

(4) Both methods of measuring internal velocity of debris flows are effective and reliable for the flume experiment according to their applications in Dongchuan Debris Flow Observation and Research Station.

\section{Acknowledgement}

This study was supported by the National Natural Science Foundation of China (40771026).

\section{References}

[1] Arattano, M., Marchi, L. Measurements of debris flow velocity through cross-correlation of instrumentation data. Natural Hazards and Earth System Sciences, 5(1), pp. 137-142, 2005.

[2] Arattano, M., Deganutti, AM., Marchi, L. Debris flow monitoring activities in an instrumented watershed on the Italian Alps. In: Chen, C.L. (ed.), Proceedings of 1st International Conference on Debris-flow Hazards Mitigation: Mechanics, Prediction and Assessment. New York: ASCE, pp. 06-515, 1997.

[3] Berti, M., Genevois, R., LaHusen, R., et al. Debris flow monitoring in the Acquabona Watershed on the Dolomites (Italian Alps). Physics and Chemistry of the Earth (B), 25(9), pp. 707-715, 2000.

[4] Itakura, Y., Koga, Y., Takahama, J., et al. Acoustic detection sensor for debris flow. In: Chen, C.L. (ed.), Proceedings of $1^{\text {st }}$ International Conference on Debris-flow Hazards Mitigation: Mechanics, Prediction and Assessment. New York: ASCE, pp. 747-756, 1997.

[5] Suwa, H., Okunishi, K., Sakai, M. Motion, Debris Size and Scale of Debris Flows in a Valley on Mount Yajkedake, Japan. In: Proceedings of the International Symposium on Sediment Problems: Strategies for Monitoring, Prediction and Control. IAHS Press, Wllingford. 217, pp. 239-248, 1993.

[6] Zhang, S. A Comprehensive Approach to the Observation and Prevention of Debris Flows in China. Natural Hazards, 7, pp. 1-23, 1993.

[7] Itakura, Y., Ogawa, K., Suwa, H., et al. Trends and fluctuation of the surface-velocity of debris flow measured by a non-contact speed sensor 
with a spatial filter. In: Harada, M. (ed.), Fluid control and measurement. Tokyo: Pergamon Press, pp. 781-786, 1985.

[8] Stepanov, B.S. Main characteristics of debris flows and debris-flow deposits. Methods of measurements. In: Trudy KazNIGMI, Proceedings of Kazakh Regional Scientific Research Institute of Hydrometeorology. Moscow: Gidrometeoizdat, pp. 135, 1982. (in Russian).

[9] Prochaska, AB., Santi, PM., Higgins, JD. Relationships between Size and Velocity for Particles within Debris Flows. Canadian Geotechnical Journal, 45(12), pp. 1778-1783, 2008.

[10] Hanisch, J., Ergenzinger, P., Bonte M. Dumpling - an "Intelligent” Boulder for Studying Internal Process of Debris Flows. In: Rickenmann, D., Chen, C.L. eds., Proceedings of $3^{\text {rd }}$ International Conference on Debris-flow Hazards Mitigation: Mechanics, Prediction and Assessment. Millpress, Rotterdam, pp. 843-849, 2003.

[11] Itakura, Y., Kitajima, T., Endo, K., et al. A New Double Dual-axes Accelerometer Debris-flow Detection System. In: Wieczorek, G.F., Naeser, N.D. eds., Proceedings of $2^{\text {nd }}$ International Conference on Debris-flow Hazards Mitigation: Mechanics, Prediction and Assessment. Balkema, Rotterdam, pp. 273-281, 2000. 